\title{
Evaluation of postpartum intrauterine contraceptive devices (IUCD) insertion: 5 years study
}

\author{
Ramalingappa C. Antaratani, Vinay Raju D., Sanjana K.*
}

Department of Obstetrics and Gynecology, Karnataka Institute of Medical Sciences, Hubli, Karnataka, India

Received: 14 January 2019

Accepted: 06 February 2019

*Correspondence:

Dr. Sanjana K.,

E-mail: sanjanak60.sk@gmail.com

Copyright: () the author(s), publisher and licensee Medip Academy. This is an open-access article distributed under the terms of the Creative Commons Attribution Non-Commercial License, which permits unrestricted non-commercial use, distribution, and reproduction in any medium, provided the original work is properly cited.

\begin{abstract}
Background: The intrauterine contraceptive device (IUD) primarily in the form of copper T is used by more than 150 million women around the world making it the most widely used reversible method of contraception with a remarkably low failure rate of less than 1 per 100 women in the first year of use for cu T $380 \mathrm{~A}$. It is more suitable for a country like India which is in urgent need of population control methods.

Methods: A Prospective observational study was under taken where in a series of women who delivered either vaginally or through caesarean section during the period of November 2013 to October 2017 in the Department of Obstetrics and Gynecology, Karnataka Institute of Medical Sciences, Hubli counseled for PPIUCD insertion were included in the study. Mothers who were suffered from Chorioamnionitis, Puerperal sepsis, Postpartum haemmorrhage, PROM more than 18 hours, extensive genital trauma, uterine abnormalities, Multiple sexual partners and obstructed labour were excluded from the study. Since it was a time bound study, a total of 16009 cases were enrolled in the study after counseling them.

Results: A total of 16009 women were counseled to undergo PPIUCD, out which 5144 women accepted for PPIUD amounting to a total acceptance rate of $32.1 \%$. Out of the 10865 women who did not accept device, the reason for nonacceptance preference another contraception $60 \%$, family opposition was reason in $21 \%$ of women, while $08 \%$ of women had side effects from their previous use. $11 \%$ of women said that they were not desire to use contraception.

Conclusions: Family planning and mother and child health services are supplied to the people free of cost in India. Use of an intrauterine device is simpler, less expensive, and immediately reversible.
\end{abstract}

Keywords: Less expensive, PPIUCD, Reversible contraceptive

\section{INTRODUCTION}

India is the second most populated country in the world after china with more than a billion people and having a maternal mortality rate of 254/100.000 live birth. India has one of the highest numbers of maternal death in the world. Indian women have more children than desired and often too closely together due to limited choice of quality, family planning services and the urgent need of family planning. Short intervals between births are linked to higher maternal and child mortality and morbidity. ${ }^{1}$
Insertion of Intra Uterine Contraceptive Devices (IUCDs) early in the postpartum period represents a convenient opportunity for the administration of a safe, highly effective, long acting, cost effective reversible and easy to insert contraceptive method. Insertion of an intrauterine contraceptive device (IUCD) immediately after delivery has been recommended by World Health Organization (WHO), as one of the safe and effective methods of the temporary contraception. ${ }^{2}$ Postpartum family planning (PPFP) is the prevention of unintended and closely spaced pregnancies through the first twelve 
months following childbirth. ${ }^{3}$ There are many options available for postpartum contraception viz. lactational amenorrhea (LAM method), Pills, IUCD, Condom, sterilization but the women in the postpartum period wants an efficacious, reliable, safe, easy to use and a reversible contraceptive method which provide long term protection. All these criteria's are fulfilled by PPIUCD.

In the immediate post delivery period, the women are highly motivated and need an effective method of contraception so that the child can be brought up with a relaxed mind without the worry of unintended pregnancy. On the other hand, if they are made to wait for 6 weeks for initiating an effective contraception, they may conceive accidently or may not come for contraception. This approach is more applicable to our country where delivery may be the only time when a healthy woman comes in contact with health care personnel. Compared with sterilization, however, use of an IUCD is simpler, less expensive and immediately reversible. With this background authors have under taken the present study to assess the acceptance and complications of usage of postpartum IUCDs.

\section{METHODS}

A Prospective observational study was under taken where in a series of women who delivered either vaginally or through caesarean section during the period of November 2013 to October 2017 in the Department of Obstetrics and Gynecology, Karnataka Institute of Medical Sciences, Hubli counseled for PPIUCD insertion were included in the study.

\section{Exclusion criteria}

- Mothers who were suffered from Chorioamnionitis, Puerperal sepsis, Postpartum haemmorrhage, PROM more than 18 hours, extensive genital trauma, uterine abnormalities, Multiple sexual partners and obstructed labour were excluded from the study.

Since it was a time bound study, a total of 16009 cases were enrolled in the study after counselling them.

\section{Steps involved}

- After counseling and after taking due consent of the women for insertion, PPIUCD (Cu T 380 A) was inserted during postpartum period either during post placental or immediate postpartum period within 48 hours after delivery or during caesarean depending upon the consent and mode of delivery of the women.

- The women was then explained regarding potential adverse effects, care and further follow up visits and is then discharged.

- The women was called after 6 weeks for first follow up.
- During follow up period, patient was first asked about any complaints she was having about $\mathrm{CuT}$. And if yes, then symptomatic treatment was given.

- Then CuT thread was examined by per speculum examination.

- If CuT thread was not found, then the position of $\mathrm{CuT}$ is confirmed by ultrasonographic examination.

- If CuT was situ, then patient was counseled about the position and safety of the CuT.

- Then again, the patient was called after 3 months for follow up and the same methodology followed.

- All the above events and the respective findings were recorded.

\section{Statistical analysis}

All the collected data variables was entered into an excel sheet and after appropriate data filtration, the data sheet was transferred to and analyzed using SPSS software version 22 .

Appropriate descriptive statistics were used to describe the data and appropriate tests of significance were applied to find out the associations between the variables.

\section{RESULTS}

Maximum study subjects were in the age group 18-25yrs $(66 \%)$. A large proportion of them were hindus $(87.5 \%)$. About half of the study subjects were home makers. $46.2 \%$ of them were illiterates and $34.2 \%$ had done their primary schooling (Table 1).

Table 1: Socio-demographic profile of the study subjects.

\begin{tabular}{|l|l|l|l|}
\hline Variable & & Frequency & $\%$ \\
\hline Age group & 18-25 years & 10565 & 66.0 \\
\hline & 26-30 years & 4610 & 28.8 \\
\hline & 31-35 years & 800 & 5.0 \\
\hline & 36 years & 34 & 0.2 \\
\hline Religion & Hindus & 16009 & 100.0 \\
\hline & Muslims & 14023 & 87.5 \\
\hline & Christians & 1600 & 10.1 \\
\hline & & 386 & 2.4 \\
\hline Occupation & Housewife & 8357 & 52.2 \\
\hline & Unskilled labour & 5330 & 33.3 \\
\hline & Skilled labour & 1616 & 10.1 \\
\hline & Self employed & 706 & 4.4 \\
\hline & & 16009 & 100.0 \\
\hline & Illiterate & 7396 & 46.2 \\
\hline & Primary schooling & 5475 & 34.2 \\
\hline & High schooling & 1633 & 10.2 \\
\hline & PUC & 1152 & 7.2 \\
\hline & Degree & 353 & 2.2 \\
\hline & & 16009 & 100.0 \\
\hline
\end{tabular}


Nearly half of the study subjects were primigravidae (48.6\%) and $43.4 \%$ were multigravidae with 1 child these being the target population for spacing methods like cu $\mathrm{T}$ insertion (Table 2).

Table 2: Obstetric profile of the study subjects.

\begin{tabular}{|l|l|l|}
\hline Obstetric profile & Frequency & $\%$ \\
\hline Primigravida & 7780 & 48.6 \\
\hline Multigravida with 1 child & 6948 & 43.4 \\
\hline Multigravida with 2 or more child & 1281 & 8.0 \\
\hline Total & 16009 & 100.0 \\
\hline
\end{tabular}

A total of 16009 women were counselled to undergo PPIUCD, out which 5144 women accepted for PPIUCD amounting to a total acceptance rate of $32.1 \%$.

The acceptance rate was more in the young age groups 18-25 years $(33.8 \%)$ and $26-30$ years $(30.1 \%)$ when compared to elder age groups $31-35$ years $(22.5 \%)$ and more than 35 years $(16.7 \%)$.

The acceptance of PPICUD was high among Christian Women $(35 \%)$ compared to Hindu women $(33.2 \%)$ and Muslim women $(22.1 \%)$.

Table 3: Socio-demographic profile versus acceptance rate among the study subjects.

\begin{tabular}{|l|l|l|l|l|}
\hline Variable & & Total no. of patients (N) & No. of patients accepted (N) & Percentage \\
\hline Age Group & 18-25 years & 10566 & 3571 & 33.8 \\
\hline & $26-30$ years & 4610 & 1387 & 30.1 \\
\hline & $31-5$ years & 800 & 180 & 22.5 \\
\hline & $>36$ years & 33 & 6 & 16.7 \\
\hline Religion & Hindus & 16009 & 5144 & 32.1 \\
\hline & Muslims & 1623 & 4655 & 33.2 \\
\hline & Christians & 371 & 357 & 22.1 \\
\hline Occupation & House wife & 16009 & 132 & 35.0 \\
\hline & Unskilled labour & 5336 & 5144 & 32.1 \\
\hline & Skilled labour & 1600 & 2599 & 31.1 \\
\hline & Self employed & 722 & 1695 & 31.8 \\
\hline & & 16009 & 580 & 36.3 \\
\hline Education & Illiterate & 7396 & 270 & 37.3 \\
\hline & Primary schooling & 5475 & 5144 & 32.1 \\
\hline & High schooling & 1632 & 2263 & 30.6 \\
\hline & PUC & 1153 & 1692 & 30.9 \\
\hline & Degree & 353 & 612 & 37.5 \\
\hline & & 443 & 38.4 \\
\hline & & 16009 & 5144 & 37.9 \\
\hline
\end{tabular}

The acceptance rate was more among self-employed $(38 \%)$ and skilled labour women $(36.3 \%)$ compared other women with other occupations. Educated women had higher acceptance rate school $37.5 \%$, PUC $38.4 \%$, Degree $39.7 \%$ ) compared to women who were illiterate and with primary Schooling $(30.6 \%$ and $30.9 \%$ respectively) (Table 3 ). The acceptance rate of PPIUCD was high among multigravida women with one child (38.7\%) when compared to multigravida with 2 or more children $(30.9 \%)$. The acceptance rate was less among primigravida women $(26.5 \%)$ (Table 4$)$.

The acceptance rate was more among women who were counseled during the early labour (36.9\%) when compared to women who were counseled during antepartum (29\%) and postpartum period (26.6\%) (Table 5)
Table 4: Obstetric profile versus acceptance rate among the study subjects.

\begin{tabular}{|l|l|l|l|}
\hline $\begin{array}{l}\text { Obstetric } \\
\text { proffle }\end{array}$ & $\begin{array}{l}\text { Total no of } \\
\text { patients (N) }\end{array}$ & $\begin{array}{l}\text { No. of patients } \\
\text { accepted (n) }\end{array}$ & $\%$ \\
\hline $\begin{array}{l}\text { In primigravida } \\
\begin{array}{l}\text { In multigravida } \\
\text { with 1 child }\end{array}\end{array}$ & 6780 & 2062 & 26.5 \\
\hline $\begin{array}{l}\text { In multigravida } \\
\text { with 2 or more } \\
\text { child }\end{array}$ & 1297 & 2682 & 38.7 \\
\hline Total & 16009 & 5144 & 30.9 \\
\hline
\end{tabular}

Out of the 10865 women who did not accept device, the reason for non-acceptance preference another contraception $60 \%$, family opposition was reason in $21 \%$ of women, while $08 \%$ of women had side effects from 
their previous use. $11 \%$ of women said that they were not desired to use contraception (Table 6).

Table 5: Period of counselling versus acceptance rate among the study subjects.

\begin{tabular}{|l|l|l|l|}
\hline $\begin{array}{l}\text { Period of } \\
\text { counselling }\end{array}$ & $\begin{array}{l}\text { Total no. of } \\
\text { patients (N) }\end{array}$ & $\begin{array}{l}\text { No. of patients } \\
\text { accepted (n) }\end{array}$ & $\%$ \\
\hline Antepartum & 6627 & 1921 & 29.0 \\
\hline Early labour & 7060 & 2605 & 36.9 \\
\hline Postpartum & 2322 & 618 & 26.6 \\
\hline Total & 16009 & 5144 & 32.1 \\
\hline
\end{tabular}

Table 6: Reasons for not accepting PPIUCD.

\begin{tabular}{|l|l|l|}
\hline Reason & $\begin{array}{l}\text { No. of } \\
\text { patients }\end{array}$ & $\%$ \\
\hline Preference for another contraceptive & 6519 & 60 \\
\hline Family opposition & 2281 & 21 \\
\hline Side effects from previous use & 870 & 08 \\
\hline No contraception & 1195 & 11 \\
\hline Total & 10865 & 100.0 \\
\hline
\end{tabular}

Among the other method of family planning that as chosen by the women who did not accept the PPIUCD, $29.4 \%$ choose to continue with lactational amenorrhea. $32.00 \%$ started using barrier contraceptives, $27.5 \%$ went with hormonal contraceptives and $11.1 \%$ women choose permanent sterilization. Some said will come back after some time for sterilization (Table 7).

Table 7: Preferred method of contraception among subjects who did not accept PPIUCD.

\begin{tabular}{|l|l|l|}
\hline Preferred method & No. of patients & $\%$ \\
\hline Lactational amenorrhoea & 2843 & 29.4 \\
\hline Permanent sterilization & 1074 & 11.1 \\
\hline Barrier contraception & 3094 & 32.0 \\
\hline Hormonal contraceptives & 2659 & 27.5 \\
\hline Total & 9670 & 100.0 \\
\hline
\end{tabular}

Out of 5144 inserted PPIUCD devices $27 \%$ of them were inserted in Post placental period, $20 \%$ in immediate postpartum period, while $53 \%$ of them were inserted during delivery by caesarean section (Table 8).

Table 8: Time of placement of PPIUCD among the accepted patients.

\begin{tabular}{|l|l|l|}
\hline Type of PPIUCD & No. of patients & $\%$ \\
\hline Post placental & 1389 & 27 \\
\hline Immediate postpartum & 1029 & 20 \\
\hline Intracaesarean & 2726 & 53 \\
\hline Total & 5144 & 100 \\
\hline
\end{tabular}

Out of 5144 women who had accepted PPIUCD, at the end of 6 weeks of follow up, the predominant complaints were abdominal pain (25\%), heavy vaginal bleeding
(15\%), thread coming out (8\%) followed by spontaneous expulsion (5.1\%) and missing thread (1.4\%) (Table 9).

Table 9: Predominant complaints after 6 weeks and 3 months of placement of PPIUCD among the accepted patients.

\begin{tabular}{|l|l|l|}
\hline Complaints at 6 weeks & $\begin{array}{l}\text { After 6 weeks } \\
\text { N }(\%)\end{array}$ & $\begin{array}{l}\text { After 3 } \\
\text { months } \\
\text { N }(\%)\end{array}$ \\
\hline No complaints & $2057(40)$ & $4012(77.7)$ \\
\hline Abdominal pain & $1286(25.0)$ & $771(15.1)$ \\
\hline Heavy bleeding & $771(15)$ & $180(3.59)$ \\
\hline Thread coming out & $411(8)$ & $51(1.0)$ \\
\hline Expulsion & $258(5.1)$ & $308(6.0)$ \\
\hline Missing Thread & $72(1.4)$ & $10(0.2)$ \\
\hline Lost to follow up & $617(12.0)$ & $1568(30.5)$ \\
\hline Perforation & $0(0.0)$ & $0(0.0)$ \\
\hline $\begin{array}{l}\text { Pregnancy with copper } \\
\text { in situ }\end{array}$ & $0(0.0)$ & $0(0.0)$ \\
\hline
\end{tabular}

At the end of 3 months of follow up, the predominant complaints were abdominal pain $(15.1 \%)$ heavy vaginal bleeding $(3.59 \%)$, spontaneous expulsion $(6 \%)$ followed by thread coming out $(1 \%)$ and missing thread $(0.2 \%)$

At the end of 6 weeks $617(12 \%)$ of the women were lost to follow up and $1568(30.5 \%)$ of them were lost to follow up after 3 months.

There were total of $592(11.5 \%)$ spontaneous expulsions, $258(5.1 \%)$ of them were early expulsions (within 6 weeks) while $308(6.0 \%)$ was delayed expulsion that took place between 6 weeks to 3 months. And at the end of 1 years $26(0.5 \%)$ were expulsed (Table 10$)$.

Table 10: Expulsion rate among the total PPIUD accepted subjects $(\mathrm{N}=\mathbf{5 1 4 4})$.

\begin{tabular}{|l|l|l|}
\hline Follow up Interval & No. of Patients & $\%$ \\
\hline At 6 weeks & 258 & 5.1 \\
\hline At 3 months & 308 & 6.0 \\
\hline At 1 years & 26 & 0.5 \\
\hline Total & 592 & 11.5 \\
\hline
\end{tabular}

Table 11: Causes for removal of PPIUCD among the total accepted subjects $(\mathrm{N}=5144)$.

\begin{tabular}{|l|l|l|}
\hline Causes of removal & No. of patients & $\%$ \\
\hline Abdominal plain & 1157 & 22.5 \\
\hline Heavy bleeding & 150 & 2.95 \\
\hline Missing thread & 82 & 1.6 \\
\hline For tubectomy & 360 & 7.0 \\
\hline Family opposition & 257 & 5.0 \\
\hline Pregnancy & 0 & 0.0 \\
\hline Total & 2006 & 38.99 \\
\hline
\end{tabular}

At total of 2006 (38.99\%) PPIUCDs had to be removed because $1157(22.5 \%)$ of them had unrelieved abdominal 
pain, $150(2.95 \%)$ had uncontrolled heavy vaginal bleeding, while in $82(1.6 \%)$ patients it was removed because thread was missing followed by patient request. $360(7.0 \%)$ got removed and underwent tubectomy (Table 11).

\section{DISCUSSION}

For sexually active fertile woman who do not use contraception, pregnancy rates approach 90 percent at one year. In the immediate post delivery period, the women are highly under the risk of accidental pregnancy and in this time period they are highly motivated and need an effective method for contraception. As per Indian scenario many women at this period may not yet be ready for a terminal method of permanent contraception such as tubal ligation, and they usually are looking for method of contraception which is temporary and reversible. A total of 16009 women were counseled to undergo PPIUD, out which 5144 women accepted for PPIUD amounting to a total acceptance rate of $32.1 \%$, which is almost similar \% to the study conducted by Mohammed SA et al. ${ }^{4}$

In 1967. the data collected by Population Council, New York, from multiple hospitals in different countries regarding various methods that were used for postpartum family planning. Among the 101,725 women who accepted the method of post-partum family planning , $51 \%$ women choose intrauterine device as their postpartum contraceptive method. ${ }^{5}$ In the present study the major reasons for non-acceptance of CU-T are preference to another contraceptive and family opposition, similar result was found in study conducted by Sharma Megha et al , family opposition remains second most common cause whereas side effects of CU-T from previous use becomes the first major reason. ${ }^{6}$

According to the study conducted in India to explore the reasons for non-acceptance of PPIUCD, the most common reasons are nonawareness of contraceptive methods, misbelieves about copper-t, male child preference. ${ }^{7}$ The acceptance rate was more in the young age groups $18-25$ years $(33.8 \%)$ and $26-30$ years $(30.1 \%)$ in present study, and according to study conducted by Kafiye Eroglua et al , the maximum number of patients i.e. $38 \%$ are in $20-24$ years age group and $26 \%$ in $25-29$ years age group. ${ }^{8}$

In the present study the acceptance rate of PPIUCD was high among multigravida women with one child (38.7\%) when compared to multigravida with 2 or more children $(30.9 \%)$. The acceptance rate was less among primigravida women $(26.5 \%)$, in contrary to the result found in the study conducted by Kafiye Erogula et al, where $44 \%$ of the patients are primipara, $36 \%$ of patients having two living children, and $19 \%$ patients having 3 or more living children. ${ }^{8}$ In the present study at the end of 6 weeks of follow up, the predominant complaints were abdominal pain (25\%), heavy vaginal bleeding (15\%), thread coming out (8\%) followed by spontaneous expulsion $(5.1 \%)$ and missing thread $(1.4 \%)$

At the end of 3 months of follow up, the predominant complaints were abdominal pain $(15.1 \%)$ heavy vaginal bleeding (3.59\%), spontaneous expulsion (6\%) followed by thread coming out $(1 \%)$ and missing thread $(0.2 \%)$. At the end of 6 weeks $617(12 \%)$ of the women were lost to follow up and $1568(30.5 \%)$ of them were lost to follow up after 3 months. Compared to the study conducted by Chi Cheng I et al only $4 \%$ of patients lost to follow up within 6 weeks was quite higher in present study. ${ }^{9}$

In the present study there were total of $592(11.5 \%)$ spontaneous expulsions, $258(5.1 \%)$ of them were early expulsions (within 6 weeks) while 308 (6.0\%) was delayed expulsion that took place between 6 weeks to 3 months. And at the end of 1 years $26(0.5 \%)$ were expulsed, which was similar to the study coated by Celen $\mathrm{S}$ et al, the 1-year cumulative expulsion rates with $\mathrm{Cu}-\mathrm{T}$ device was $12.3 \%$, which may be regarded as a standard expulsion rate for immediate post placental insertion of similar model of IUDs. ${ }^{10}$ In present study a total of 2006 (38.99\%) PPIUCDs had to be removed because 1157 $(22.5 \%)$ of them had unrelieved abdominal pain, 150 $(2.95 \%)$ had uncontrolled heavy vaginal bleeding, while in $82(1.6 \%)$ patients it was removed because thread was missing followed by patient request. 360 (7.0\%) got removed and underwent tubectomy, the results are in contrary to the study conducted by O'Hanley K et al, where the removal rate for the reason of heavy vaginal bleeding i.e. $23.6 \%$ became the important cause. ${ }^{11}$

\section{CONCLUSION}

Family planning and mother and child health services are supplied to the people free of cost in India. So as far as the birth control measures are concerned, a 'cafeteria approach' of all types of methods are offered for user to choose. IUDs are widely acceptable reversible method of contraception for spacing of births. In the immediate post delivery period, the women are highly motivated and need an effective method for contraception so that the child can be brought up without the worry of unintended pregnancy. Use of an intrauterine device is simpler, less expensive, and immediately reversible.

\section{Funding: No funding sources}

Conflict of interest: None declared

Ethical approval: The study was approved by the Institutional Ethics Committee

\section{REFERENCES}

1. RutsteinS : Further Evidence of the effects of preceding Birth intervals on Neonatal, infant and under five years Mortality and Nutritional status in Developing Countries: Evidence from the Demographic and Health Surveys. DHS Working papers No.41. Macro International; 2008. 
2. World Health Organization.Medical eligibility criteria for contraceptive use. Geneva:World Health Organisation; 2010. Available at www.who.int/reproductivehealth/publications/family planning/9789241563888/en/

3. Cleland J, Bernstein S, Faundes A, Glasier A, Innis J. Family planning the unfinished agenda. Lancet. 2006;368(9549):1810-27.

4. Aisien AO, Intrauterine Contraceptive Device(IUCD): Acceptability and Effectiveness in a Territory Institution, Afr J Med Sci. 2007;36(3):193200.

5. International Postpartum Family planning Program: Report on the First Year, Studies in Family Planning. Populat Council Publi. 1967; 1(22):p1-23.

6. Sharma M, Joshi S, Nagar O, Sharma A, Determim=nants of Intrauterine Contraceptive Device Discontinuation among Indian Woman. J Obstet Gynaecol India,2014;64(3):p208-211.

7. Sanskriti P, Amita T, Pratima M, Rupali D, Jyotsna S, Kumar A. Exploring reasons behind Low acceptance for PPIUCD in postnatal women, New Indian J Surg. 2011;2(4):p246.
8. Eroglu K, Akkuzu G, Vural G, Dilbaz B, Akin A, Taskin L, Haberal A, Comparison of efficacy and complications of IUD insertion in immediate postplacental/early postpartum period with interval period: 1 year follow up. Contracep. 2006;74: p37681.

9. Chi C, Postpartum IUD insertion: timing, route, lactation, and uterine perforation., Proceedings from the Fourth International Conference on IUDs, Boston: Butterworth Heinemann; 1994; p219-227.

10. Celen S, Moroy P, Sucak A, Aktulay A, Danisman $\mathrm{N}$, Clinical Outcomes of early postplacental insertion of Intrauterine Contraceptive Device. Contracep. 2004;69(4): p279-82.

11. O’Hanley K, Huber DH, Postpartum IUDs: Keys for success. Contracep. 1992;45(4):p351-61.

Cite this article as: Antaratani RM, Raju V, Sanjana K. Evaluation of postpartum intrauterine contraceptive devices (IUCD) insertion: 5 years study. Int J Reprod Contracept Obstet Gynecol 2019;8:1133-8. 